\title{
RHETORICAL FUNCTIONS OF CITATIONS IN LINGUISTICS RESEARCH ARTICLES: A CONTRASTIVE (ENGLISH-CZECH) STUDY
}

\author{
Olga Dontcheva-Navratilova
}

\begin{abstract}
This study explores the rhetorical functions of citations in a specialized corpus of linguistics English-medium research articles by Czech and Anglophone scholars. Drawing on the typologies suggested by Thompson and Tribble (2001), Petric (2007) and Lin, Chen and Chang (2013), the purpose of the investigation is to suggest a revised taxonomy and identify the rhetorical functions of citations in the corpus. The findings of the contrastive analysis of variation in the functions of citations and their distribution across the generic moves of research articles by Anglophone and Czech linguists indicates that there are divergences in the strategies they use to create intertextual connections when attributing knowledge or methods to others, relating their research to the work of others and evaluating previous research. The reasons for these divergences are related to the intended readership and the linguacultural context in which Anglophone and Czech linguists strive to construct their identities as members of the global and/or local academic community.
\end{abstract}

\section{Keywords}

citation typology, rhetorical functions, research articles, cross-cultural variation, academic discourse

\section{Introduction}

Citation is a prominent feature of the interpersonal dimension of academic discourse which enables authors to create intertextual connections tracing the development of scientific ideas and research methodology and thus to position themselves and their research with regard to their discourse community and prior disciplinary knowledge. Academic writers use citations as explicit means of intertextuality (Bazerman et al. 2005) to resolve tension between progress and continuity in scientific research, i.e. between claiming originality and presenting new findings, and situating oneself as a researcher in a scientific tradition (Fløttum, Dahl \& Kinn 2006: 236). The importance of citations as a rhetorical device in academic discourse stems from their potential not only to acknowledge selected previous research, but also to evaluate the work of others, to support the writers' arguments and promote their own work and knowledge claims, i.e. citation is central to academic persuasion (Hyland 1999, Petrić 2007). 
Citation practices are shaped by the disciplinary and cultural conventions in which academic authors are socialized (Shaw \& Pecorari 2013). Several studies have convincingly shown that there are substantial differences in citation practices between disciplines and genres (e.g. Thompson \& Tribble 2001, Hyland 1999, 2000, Charles 2006, Harwood 2009). Investigations into crosscultural variation in citation practices have analysed the language of origin, recency and rate of citations (e.g. Bloch \& Chi 1995, Petersen \& Shaw 2002, Hewings, Lillis \& Vladimirou 2010, Breeze 2015, Dontcheva-Navratilova 2015), thus foregrounding the significance of the geolinguistic dimension of citation practices related to the centre-periphery divide in the international academic community (Bennett 2013). Very few studies, however, have addressed crosscultural variation in rhetorical functions of citations and their distribution across the rhetorical moves of research articles (Bloch \& Chi 1995, Mur-Dueñas 2009, Dontcheva-Navratilova 2015, Hu \& Wang 2014).

This investigation explores the rhetorical functions of citations in a specialized corpus of English-medium linguistics research articles by Czech and Anglophone scholars published in the journals Applied Linguistics (AL) and Discourse and Interaction (DI). The analysis uses a revised typology of rhetorical functions of citations in an attempt to compare the range and proportion of rhetorical functions of citations and their distribution across the rhetorical moves of the research articles in the $A L$ and $D I$ sub-corpora. The aim of the study is to explain the reasons for variation in the citation practices of Czech and Anglophone writers and thus to deepen our understanding of how linguacultural background shapes the interpersonal devices that academic writers use to construct their identities as members of the global and/or local academic community and to engage in a dialogue with their colleagues.

\section{Functions of citations}

Understanding why academic writers cite and what they attempt to achieve by using citations has been the focus of numerous studies which have tried to classify citations according to different criteria, most of which can be broadly grouped into three types: content-based, formal and functional. In this section, I first review previous classifications of citations and then suggest a revised typology of rhetorical functions of citations reflecting functional, contextual and formal considerations.

\subsection{Classifying citations}

Early research into citations was carried out by information scientists (e.g. Garfield 1965, Oppenheim \& Renn 1978) who identified different reasons for 
using reference to sources when developing systems for indexing citations. Recent research into citer motivation has also considered the relative importance of citing prestigious names and works which help writers develop their argument (White 2001,2004). Several categories of citer motivation, such as paying homage to pioneers, giving credit for related work, identifying methods, correcting one's own work, criticizing other's work and substantiating claims (e.g. overall 15 categories in Garfield 1965, as cited in White 2004), have been influential on later discourse analytical studies of functions of citations in academic texts.

A different perspective is adopted in citation context analysis (Moravcsik \& Marugesan 1975, Small 1982, Lin, Chen \& Chang 2013) - a content-based analysis of functions of citations which requires subject-matter knowledge on the part of the analyst to ensure reliability (Petrić 2007). Moravcsik and Murugesan's (1975) typology, proposed within the content-based approach, analysed citations along four dimensions reflecting their contribution to the argument: whether they offer conceptual or operational support (conceptual vs operational), whether they are essential or peripheral (essential vs perfunctory), whether they directly contribute to the build-up of the main argument or not (evolutionary vs juxtapositional), and whether the writer agrees or disagrees with the original author (confirmatory vs negational). Some of these dimensions, however, have proved to be problematic when applied to different scientific disciplines; Swales (1986), for example, pointed out that the conceptual-operational dichotomy is rarely applicable outside hard sciences and replaced the essential-perfunctory division by extensive-short, which is easier to code. In a recent study of citation functions in social sciences and humanities, Lin, Chen and Chang (2013) have suggested a revised contentbased classification combining the organic(essential)-perfunctory division with the confirmative-negational dichotomy, further dividing the organic type into three sub-functions: concept, factual statement and methodology. This confirms the necessity of subject-matter-driven adjustments when applying content-based typologies to the analysis of citation functions in discipline-specific context.

Applied linguistics research focused initially on formal aspects of citations which to some extent may be seen as correlating with various rhetorical functions of citations. Thus Swales's (1986, 1990) genre-based studies introduced the distinction between integral and non-integral in-text citations (further modified by Hyland 1999 and Fløttum, Dahl \& Kinn 2006), which reflects variation in the degree of prominence given to human agency in the construction of scientific knowledge indicated by the grammatical role of the name of the cited author. Another aspect of the formal realization of citations has been explored by Shaw (1992), who studied the correlation between tense and voice, while Thompson and Ye (1991) and Hyland (1999) investigated the denotative and evaluative 
potential of reporting verbs to indicate the positive, neutral or negative stance of the writer towards prior research.

Recent investigations into rhetorical functions of citations are typically undertaken from a cross-disciplinary and pedagogical perspective and can be seen as pertaining to two broad categories: interview-based and corpus/textbased studies. The discourse-based interview approach has been applied in the analysis of self-citations (Hyland 2003) and in the investigation of interand intra-disciplinary differences in citer behaviour (Harwood 2008, 2009, Petrić \& Harwood 2013). Harwood's qualitative study has yielded a typology comprising eleven motivations/functions of citations, several of which, despite some terminological differences, broadly overlap with those suggested by earlier content-based studies (cf. Small 1982), e.g. they give credit to previous research, position with regard to viewpoints, engage in critical dialogue with sources, build on existing methods, tie authors with methods and disciplinary traditions. The application of this taxonomy, however, is problematic as it relies heavily on content/context analysis and does not consider any linguistic indicators of the rhetorical functions of citations.

Corpus-based studies tend to explore citation functions across the rhetorical moves of research articles in different disciplines (e.g. Berkenkotter \& Huckin 1995, Hyland 1999, 2000, Thompson 2000, Charles 2006, Mansourizadeh \& Ahmad 2011, Samraj 2013). For instance, Thompson and Tribble (2001) combine formal and functional criteria in their classification of integral and non-integral citations, where integral citations are categorized on the basis of formal criteria, such as the presence/absence of a controlling verb, while types of non-integral citations are identified according to functional considerations. Petrić's (2007) analysis of citations in master's theses in the field of gender studies written by second-language writers draws on Thompson and Tribble's (2001) classification to suggest a functional typology of integral and non-integral citations which comprises nine categories: attribution, exemplification, further reference, statement of use, application, evaluation, establishing links between sources and comparison of one's findings with other sources and other. The main advantage of this typology is that it relates rhetorical functions to linguistic cues signalling the role assigned to citations in relation to the cited source (e.g. see, for example, evaluative language); thus the application of this taxonomy does not require extensive content knowledge. Mansourizadeh and Ahmad (2011) apply a revised citations typology based on Thompson and Tribble (2001) and Petrić (2007) to the analysis of non-native expert and novice scientific writers to show that difference in expertise accounts for variation in the use of sophisticated, complex rhetorical functions of citations, such as establishing links between sources, support for views, methods and procedures and self-citation. Samraj's (2013) 
study underlines the importance of contextually informed analysis of citation functions in relation to rhetorical moves for an adequate understanding of the complex web of intertextual links that citations create in academic discourse.

\subsection{Typology of rhetorical functions of citations}

The typology of citations applied in this study daws on Thompson and Tribble's (2001) and Petrić's (2007) taxonomies and is further informed by Lin, Chen \& Chang's (2013) context-based classification of citations. My classification adopts the organic/perfunctory division used in content-based classifications (cf. Moravcsik \& Marugesan 1975, Small 1982, Lin, Chen \& Chang 2013), to which I refer to as essential/peripheral, to indicate the extent to which a citation is essential to the argument in the research article (Table 1). This division can bring useful quantitative insights, as essential citations are expected to yield a higher rate of occurrence; however, peripheral citations cannot be regarded as non-important as they allow writers to contextualize their work in relation to their discourse community (White 2004), create links between cited sources and can be indicative of the writer's more elaborate rhetorical skills. The confirmative/ negational division is not reflected systematically in my classification, as not only is the proportion of negative citations low (Small 1982, White 2004), but also any type of citation may imply support for or criticism of the cited author's work. For the subdivision of the essential and peripheral types, I used as a starting point the citation categories from Petrić (2007), which comprise nine rhetorical functions: attribution, exemplification, further reference, statement of use, application, evaluation, establishing links between sources, comparison of one's findings with other sources and other. In what follows, the illustrative examples are taken from the corpus under investigation; DI marks the Czech English-medium corpus comprising research articles from the journal Discourse and Interaction, $A L$ indicates Anglophone articles from the journal Applied Linguistics; the number refers to specific texts in the corpora.

\subsubsection{Essential rhetorical functions of citations}

The rhetorical functions of attribution, statement of use of works, concepts, theories or approaches, establishing links between sources and comparison of one's findings with other sources have been included in the essential citations category, as they are related to key moves in the rhetorical structure of research articles (Swales 2004, Biber, Connor \& Upton 2007) and therefore contribute decisively to the build-up of the author's argument.

The central function of citations is to attribute a proposition to another author, i.e. they indicate where the idea, concept or method comes from. Many 
'attribution' citations are used to support the writer's argument or claim and to justify the use of methods and procedures (cf. the 'support' function, treated as a separate citation function by Mansourizadeh \& Ahmad 2011). Since the 'attribution' category in Petrić's taxonomy accounts for the majority of citations (78.77\% of all rhetorical functions of citation in high (A) rated theses and $91.54 \%$ in low (B) rated theses in her corpus) and thus does not allow for specification of what exactly is attributed to previous research, it was initially split into three categories: 'attribution of ideas, activity or concepts', 'attribution of methods or approaches' and 'attribution of factual statements', which correspond to the subtypes of essential/organic moves in Lin, Chen and Chang's (2013) taxonomy. The assumption that expert writers are likely to elaborate in greater detail on methods and approaches adopted in their research was shown to provide a sound reason for the inclusion of the attribution of methods or approaches function; however, the initial coding of rhetorical functions of citations in my data showed that the occurrence of the 'attribution of factual statements' function was insignificant, most probably due to disciplinary differences; therefore, this category has not been applied in the present research. Thus this typology considers two types of attribution with the purpose of acknowledging the contribution of previous research to the development of disciplinary knowledge:

- attribution of ideas, activity or concepts to other authors

(1) Halliday and Hasan treat LC [Lexical Cohesion] as "selecting the same lexical item twice, or selecting two that are closely related" (1976: 12). (DI3)

- attribution of methods, approaches or procedure to other authors

(2) A third approach to emergence in lexicons is illustrated in work by McNellis and Blumstein (2001). (AL6)

The 'application' category introduced by Petrić (2007: 244) to refer to the "use of arguments, concepts, terminology or procedures from the cited work for the writer's own purposes" has been merged with the 'statement of use category' as it did not yield significant occurrences, while the 'establishing links between sources' and 'comparison of one's findings with other sources' have been applied without any modifications:

- statement of use of works, concepts, theories or approaches

(3) We mainly draw on Schegloff's (1968) model of telephone openings, Schiffrin's model of opening encounters (1977) and studies dealing with Internet Relay Chat openings (Rintel et al. 2001, Ahti \& Lähtevänoja 2004). (DI9) 
- establishing links between sources pointing to similarities or contrast between concepts, methods or approaches, ideas, claims and results reported in different sources

\begin{abstract}
Altenberg (1998; Altenberg and Eeg-Olofsson 1990) was probably the first researcher to study recurrent word sequences in English (based on the LondonLund Corpus), while Butler (1997) adopted a similar approach for his analysis of recurrent word sequences in a large corpus of Spanish texts. (AL5)
\end{abstract}

- comparison of one's findings with other sources with the purpose of highlighting whether the results reported in the article support or contradict previous research

(5) Regarding the number of sentences necessary for such a summary we have arrived at 31.4 per cent, which is in harmony with de Oliveira et al. (2002), who claim for around 3 per cent of the size of the original text. (DI3)

Thus the essential category in my classification comprises five rhetorical functions which can be realized by integral and non-integral citations, although the 'establishing links between sources' and 'comparison of one's findings with other sources' categories are typically realized by non-integral forms.

\title{
2.2.2 Peripheral rhetorical functions of citations
}

Peripheral citations include four rhetorical functions: exemplification, further reference, explicit evaluation and other. A feature shared by most peripheral citations (the only exception being the category 'other') is that they are signalled by linguistic cues; this explicit marking is interpreted here as an indicator of their non-essential status. While I have adopted Petrić's terms and definitions for the 'exemplification' and 'further reference' functions, I use the term 'explicit evaluation' instead of 'evaluation' to indicate that while many citations may implicitly evaluate the information provided by the cited work, only citations marked by evaluative language are coded as pertaining to this category:

- exemplification, usually signalled by for example/instance or e.g., supporting the author's statement by referring to sources dealing with a specific issue

Geoffrey Miller (1999, 2000), for instance, argues that human languages are much more elaborate than they need to be to serve purely communicative purposes. (AL10)

- further reference, usually signalled by see or $c f$., referring the reader to further sources dealing with the topic at hand, thus contextualizing the writer's study within the related field 
(7) It has long been accepted that developing the skill of effective writing involves, amongst other things, developing an awareness of the audience and an ability to reflect and exploit that awareness in the way the text is written (see e.g. Nystrand 1986; Kirsch and Roen 1990; Grabe and Kaplan 1996; Johns 1997). (AL2)

- explicit evaluation, marked by the use of evaluative adverbs, factive and counter-factive verbs or clauses indicating the positive or critical attitude of the author towards the cited source

(8) Steels argues strongly that these 'existence proofs' should scale up to much larger lexicons, but he does not actually show that this is the case. (AL7)

Another modification concerns the definition of the 'other' category: while Petric uses it to refer to instances where the relationship between the citing sentence and the citation is obscure, I use it to refer to citations which are not related directly to the author's argument, such as the acknowledgement of examples taken from other sources or software used for the processing of data, i.e. this function is similar to Thompson and Tribble's (2001) 'origin' category:

- other

(9) Therefore, a combination of quantitative and qualitative methods, which ranges from a macro-investigation by Wordsmith Tools (Scott 1996) to a micro-discourse analytic examination through observation, is used in the study. (AL8)

\begin{tabular}{|l|l|}
\hline \multicolumn{2}{|c|}{ Typology of rhetorical functions of citations } \\
\hline $\begin{array}{l}\text { Essential } \\
\text { citations }\end{array}$ & $\begin{array}{l}\text { - attribution of ideas, activity or concepts to an author } \\
\text { - attribution of methods, approaches or procedure to an author } \\
\text { - establishing links between sources } \\
\text { - comparison of one's findings with other sources }\end{array}$ \\
\hline $\begin{array}{l}\text { Peripheral } \\
\text { citations }\end{array}$ & $\begin{array}{l}\text { - exemplification referring to source(s) illustrating the author's statement } \\
\text { - further reference to works providing additional information on the issue } \\
\text { - explicit evaluation marked by the use of evaluative language } \\
\text { - other not related directly to the uses of argumentation }\end{array}$ \\
\hline
\end{tabular}

Table 1: Typology of rhetorical functions of citations

Obviously, by adopting some content-based criteria, this typology is bound to be discipline-specific and would require some modification to allow for application in other scientific disciplines in fields of the humanities and social sciences. Another limitation is the restriction of the confirmative-negational 
divide to the 'explicit evaluation' category, which inevitably results in a failure to account for numerous supportive and critical attitudes expressed without the use of explicit language markers. Further research is necessary to refine the categories and expand the analytical framework.

\section{Data and methodology}

This contrastive study applies the typology of rhetorical functions of citations suggested above in order to explore how Anglophone and Czech linguists use citations as an interpersonal resource in research articles. The study draws on genre analysis as elaborated by Swales $(1990,2004)$ and Bhatia $(1993,2004)$ and takes an intercultural perspective (Connor 2004) that seeks to highlight differences in the distribution and types of rhetorical functions of citations used by Anglophone and Czech authors across the generic structure of research articles.

The investigation has been carried out on a small specialized corpus of 20 research articles written in the period 2001-2015 comprising ten research articles by native speakers of English (judging by their names and affiliations) published in the Oxford journal Applied Linguistics (Impact Factor 3.250, 2015 Web of Science Data) and ten English-medium research articles written by Czech linguists and published in the Masaryk University (Brno, Czech Republic) English-medium journal Discourse and Interaction (founded in 2008). While these journals clearly differ in terms of readership and academic reputation, they are considered to provide representative samples of research articles produced by Anglophone and Czech linguists respectively and are therefore expected to yield relevant results for the purposes of this contrastive analysis. Given the small size of the corpus there is a certain risk of confounding idiosyncratic with culturally-determined behaviour (Anderson \& Piazza 2005: 159); however, small specialized corpora which "allow for more top-down, qualitative, contextuallyinformed analyses than those carried out using general corpora" (Flowerdew L. 2004: 18) have proved to be very useful for contrastive studies of academic and professional discourse (e.g. Petrić 2007, Vázquez \& Giner 2008, Mur-Dueñas 2009, Harwood 2009, Povolná 2013). In order to minimize the influence of idiosyncratic citation practices, the corpus was compiled so as to represent an equal number of authors per lingua-cultural background (10 Anglophone and 10 Czech), although due to a divergence in article length the sizes of the Anglophone and Czech parts of the corpus differ in terms of word count: 77,000 words in the Applied Linguistics corpus and 48,000 words in the Discourse and Interaction corpus. This divergence in word count is regarded as a minor limitation, as it is informative to estimate the rate of citations per paper/author in terms of percentages as well as per number of words in order to identify citation density. 
The initial stage of the analysis aimed at identifying citations using Hyland's (2000) and Petrić's (2007) criteria, i.e. citations were counted irrespective of their surface realizations (author's name followed or not followed by year of publication, reference to previously mentioned source via personal pronoun or expressions such as "these researchers") in the main text of research articles, while endnotes and footnotes were not taken into consideration. Then both integral and non-integral citations were coded according to the typology of rhetorical functions described in Section 2, which comprises five categories of essential citations and four categories of peripheral citations. Although citations are often multifunctional, for the purposes of the quantitative analysis in this investigation each citation was assigned one main function on the basis of linguistic cues in the citing sentence indicating the writer's motivation for referring to the source (cf. Petrić 2007: 242). In the absence of explicit linguistic cues, multifunctionality was resolved by prioritizing essential over peripheral functions and attribution over other essential functions of citations.

\section{Findings and discussion}

The contrastive analysis of the range and rate of rhetorical functions of citations and their distribution across the rhetorical moves of research articles in the $A L$ and $D I$ sub-corpora aims at identifying and explaining reasons for the existing variation in the use of these intertextual means.

\subsection{Contrastive analysis of the frequency of occurrence of rhetorical functions of citations}

The rhetorical functions of citations in all research articles were identified and their rate of occurrence in the Applied Linguistics and Discourse and Interaction sub-corpora compared. The results of the contrastive quantitative analysis summarized in Table 2 show that there are significant differences in the rate of occurrence and ratio of essential to peripheral citations in the two sub-corpora. The frequency of occurrence of essential citations is considerably higher in the $A L$ sub-corpus than in the $D I$ sub-corpus (501 in the $A L$ sub-corpus vs 266 in the $D I$ corpus) and the difference is even more marked in the case of peripheral citations (141 in the $A L$ sub-corpus vs 43 in the $D I$ corpus). The ratio of essential to peripheral citations in the $A L$ and $D I$ research articles also differs. While in both sub-corpora essential citations clearly predominate, Czech linguists opt for a higher percentage of essential citations (86\%) than Anglophone authors (78\%) and the proportion of peripheral citations in the $D I$ research articles is lower (14\%) than in the $A L$ sub-corpus (22\%). 


\begin{tabular}{|l|c|c|c|c|}
\hline \multirow{2}{*}{ Rhetorical function } & \multicolumn{2}{|c|}{$\boldsymbol{A L}$ corpus } & \multicolumn{2}{c|}{ DI corpus } \\
\cline { 2 - 5 } & Raw No & $\%$ & Raw No & $\%$ \\
\hline Essential & 501 & 78 & 266 & 86 \\
\hline Peripheral & 141 & 22 & 43 & 14 \\
\hline Total & 642 & 100 & 309 & 100 \\
\hline
\end{tabular}

Table 2: Essential and peripheral functions of citations in the $A L$ and $D I$ corpora (\%)

These results are in agreement with the findings of previous cross-cultural research (Mur-Dueňas 2009 on Spanish vs American research articles, Hu \& Wang 2014 on Chinese vs English research articles, Dontcheva-Navratilova 2015 on Czech vs Anglophone research articles), indicating that non-native speakers generally tend to use fewer citations than Anglophone authors. This supports the view that not only expertise (cf. Petrić 2007, Samraj 2013), but also language and linguacultural background are important variables in contrastive citation analysis. Thus the use of English as a lingua franca is seen here as a factor affecting the use of rhetorical functions of citations by Czech scholars, as writing in a foreign language is likely to affect the mode of expression and the rhetorical strategies non-Anglophone scholars opt for in their academic discourse (cf. Flowerdew J. 2008). The epistomological and literacy traditions and the interaction conventions of the Anglophone and Czech linguistics discourse communities have a significant impact on citation practices (cf. Hu \& Wang 2014). The prominent tendency to contextualize research, justify choices and relate to various theoretical frameworks and methods in all articles by AL writers may stem from the multicultural, competitive character of the large Anglophone academic discourse community, in which persuasion is related to logical argumentation and negotiation of meaning. Citations enable authors to let diverse voices into their discourse and thus open up a dialogic space for the negotiation of the writer's views and claims. On the other hand, the small Czech linguistics community, which seems to be marked by symbiosis and avoidance of tension, shows a preference towards respect for established scholarly authorities, conceptual and terminological clarity associated with a more narrative style and a lower degree of interactiveness (Čmejrková \& Daneš 1997, DontchevaNavratilova 2013a) which does not require frequent use of citations.

The percentages of different rhetorical functions of citations in the $A L$ and $D I$ sub-corpora show that within the essential category, the most common function of citations in both sub-corpora is attribution of ideas, activities and concepts 
(Table 3). However, while this function accounts for less than half of the overall functions of citations in the $A L$ corpus (46.57\%), in the $D I$ corpus its frequency is higher as it is conveyed by approximately two thirds of the citations $(67.63 \%)$. The use of citations for attribution of methods and approaches is slightly more frequent in the $A L$ corpus (7.47\%) than in the $D I$ sub-corpus (5.17\%). Attribution citations (broadly overlapping with 'acknowledge' and 'distance' citations in $\mathrm{Hu}$ \& Wang 2014) are used to show knowledge of relevant views, theories, methods and findings, without indicating relationship between previous research and the author's work and without passing explicit evaluative judgement. Since these unmarked functions of citations are not integrated directly into the writer's argument, they are considered rhetorically simple. Non-attributional citations are regarded as rhetorically complex as they involve an analytical approach and transformation of knowledge associated with establishing connections between various sources, evaluating previous research and relating it to the writer's findings and claims (cf. Petrić 2007: 247).

\begin{tabular}{|l|c|c|c|c|}
\hline \multirow{2}{*}{ Rhetorical function } & \multicolumn{2}{|c|}{$A L$ corpus } & \multicolumn{2}{c|}{ DI corpus } \\
\cline { 2 - 5 } & Raw No & $\%$ & Raw No & $\%$ \\
\hline Essential citations & & & & \\
\hline Attribution of idea/activity/concept & 299 & 46.57 & 209 & 67.63 \\
\hline Attribution of methods/approaches & 48 & 7.47 & 16 & 5.17 \\
\hline Statement of use of works/concepts, methods & 36 & 5.60 & 22 & 7.11 \\
\hline Links between sources & 98 & 15.26 & 20 & 6.47 \\
\hline Comparison of one's findings with other sources & 20 & 3.11 & 3 & 0.97 \\
\hline Peripheral citations & & & & \\
\hline Exemplification & 40 & 6.23 & 24 & 7.76 \\
\hline Further reference & 65 & 10.12 & 14 & 4.53 \\
\hline Evaluation & 23 & 3.58 & 2 & 0.64 \\
\hline Other & 13 & 2.02 & 3 & 0.97 \\
\hline
\end{tabular}

Table 3: Rhetorical functions of citations in the $A L$ and $D I$ corpora (\%)

The most striking differences between the $D I$ and $A L$ sub-corpora concern the percentages of citations indicating links between sources (15.26\% in $A L$ research 
articles vs $6.47 \%$ in $D I$ research articles), comparison of one's findings with other sources (3.11\% in $A L$ research articles vs $0.97 \%$ in $D I$ research articles), further reference $(10.12 \%$ in $A L$ research articles vs $4.53 \%$ in $D I$ research articles), and evaluation (3.58\% in $A L$ research articles vs $0.64 \%$ in $D I$ research articles). The lower incidence of these citation functions in research articles by Czech linguists is associated with the scarce realization of several optional steps (e.g. reference to previous research) in some rhetorical moves in the sections of $D I$ research articles. The limited use of non-attributive essential and peripheral citations in the $D I$ corpus (as well as in the Chinese research articles analysed by $\mathrm{Hu} \&$ Wang 2014) suggests that cross-cultural variation is more prominent in the case of rhetorically complex citations. These citations are also more difficult to acquire, as evidenced by research into expert and novice academic writers (Mansourizadeh \& Ahmad 2011) and master's and doctoral students' academic discourse (Dong 1996, as cited in Petrić 2007) indicating that students need instruction in use of rhetorically complex citations and that higher-rated theses display a higher percentage of these citations than lower-rated texts (Petrić 2007).

\subsection{Contrastive analysis of the distribution of rhetorical functions of citations across the rhetorical moves of RAs in the AL and DI corpora}

An analysis of the distribution of citations across the sections of research articles shows that in agreement with the findings of previous research (MurDueñas 2009, Dontcheva-Navratilova 2015) most of the citations in both subcorpora occur in the Introduction sections $(58.56 \%$ in the $A L$ sub-corpus and $60.84 \%$ in the $D I$ sub-corpus). In terms of percentages, there are relatively small differences between the $A L$ and $D I$ sub-corpora, apart from in the percentage of citations in the Discussion section, which indicate that Anglophone authors create more intertextual links to justify their claims and support their views when discussing their findings (Table 4).

\begin{tabular}{|l|c|c|c|c|c|c|c|c|}
\hline \multirow{2}{*}{$\begin{array}{l}\text { Rhetorical } \\
\text { function }\end{array}$} & \multicolumn{2}{|c|}{ Introduction } & \multicolumn{2}{c|}{ Method } & \multicolumn{2}{c|}{ Results } & \multicolumn{2}{c|}{ Discussion } \\
\cline { 2 - 9 } & Raw No & $\%$ & Raw No & $\%$ & Raw No & $\%$ & Raw No & $\%$ \\
\hline$A L$ sub-corpus & 376 & 58.56 & 95 & 14.95 & 113 & 17.60 & 58 & 9.03 \\
\hline$D I$ sub-corpus & 188 & 60.84 & 52 & 16.82 & 51 & 16.50 & 18 & 5.82 \\
\hline
\end{tabular}

Table 4: Distribution of citations by RA section in the $A L$ and $D I$ sub-corpora 
As Table 5 shows, attribution of ideas, activities and concepts is the most prominent rhetorical function of citations in all sections of research articles in the corpus; however, the range of rhetorical functions of citations and their proportional representation in the different sections of $A L$ and $D I$ research articles vary (Table 5). Essential citations are used across all sections of the research articles in the corpus, while the occurrence of most peripheral citations outside the Introduction is relatively scarce.

\begin{tabular}{|l|c|c|c|c|c|c|c|c|}
\hline \multirow{2}{*}{ Rhetorical function } & \multicolumn{2}{|c|}{ Introduction } & \multicolumn{2}{c|}{ Method } & \multicolumn{2}{c|}{ Results } & \multicolumn{2}{c|}{ Discussion } \\
\cline { 2 - 9 } & $\boldsymbol{A L}(\%)$ & $\boldsymbol{D I}(\%)$ & $\boldsymbol{A L}(\%)$ & $\boldsymbol{D I}(\%)$ & $\boldsymbol{A L}(\%)$ & $\boldsymbol{D}(\%)$ & $\boldsymbol{A L}(\%)$ & $\boldsymbol{D I}(\%)$ \\
\hline $\begin{array}{l}\text { Attribution of ideas/ } \\
\text { activity/concept }\end{array}$ & 45.74 & 56.38 & 41.05 & 65.38 & 52.68 & 90.20 & 50.00 & 100.00 \\
\hline $\begin{array}{l}\text { Attribution of methods/ } \\
\text { approaches }\end{array}$ & 5.32 & 2.66 & 21.05 & 15.38 & 7.14 & 5.88 & 0.00 & 0.00 \\
\hline $\begin{array}{l}\text { Statement of use of } \\
\text { concepts/methods }\end{array}$ & 4.52 & 9.57 & 10.53 & 17.31 & 7.14 & 0.00 & 0.00 & 0.00 \\
\hline Links between sources & 20.48 & 10.11 & 4.21 & 0.00 & 8.04 & 0.00 & 13.79 & 0.00 \\
\hline $\begin{array}{l}\text { Comparison of findings } \\
\text { with sources }\end{array}$ & 0.00 & 1.06 & 0.00 & 0.00 & 15.18 & 1.96 & 5.17 & 0.00 \\
\hline Exemplification & 9.04 & 12.23 & 2.11 & 0.00 & 0.00 & 0.00 & 6.90 & 0.00 \\
\hline Further reference & 6.65 & 5.32 & 15.79 & 1.93 & 9.82 & 1.96 & 24.14 & 0.00 \\
\hline Evaluation & 4.79 & 0.83 & 5.26 & 0.00 & 0.00 & 0.00 & 0.00 & 0.00 \\
\hline Other & 3.46 & 1.83 & 0.00 & 0.00 & 0.00 & 0.00 & 0.00 & 0.00 \\
\hline Total & 100 & 100 & 100 & 100 & 100 & 100 & 100 & 100 \\
\hline
\end{tabular}

Table 5: Distribution of rhetorical functions of citations across the sections of RAs in the $A L$ and $D I$ sub-corpora $(\%)$

According to Swales's (1990) CARS model, Introductions of research articles comprise three rhetorical moves - Establishing territory, Establishing a niche and Occupying the niche - which are associated with a variety of rhetorical functions of citations. The Introduction sections in the $A L$ and $D I$ sub-corpora display practically all rhetorical functions of citations, as similarly to all soft sciences practitioners, linguists engage in the reiterative and recursive process of interpreting previous interpretations to lay the background for their own research 
(cf. Hyland 1999, Hu \& Wang 2014). The Establishing territory move is related to contextualizing the writer's work within prior disciplinary knowledge and thus requires reviewing of items of previous research. In both sub-corpora the most common rhetorical function associated with this move is attribution of ideas, activities and concepts $(10,11)$. Apart from mapping the field for the reader and opening a dialogic space, attribution citations enable writers to establish a professional persona by foregrounding the names of those whose work they engage with (Hyland 1999: 359). This rhetorical function is more prominent in research articles by Czech linguists (56.38\% in the $D I$ sub-corpus as compared to $45.74 \%$ in the $A L$ sub-corpus), reflecting a tendency towards a descriptive way of presentation of previous research.

(10) Ever since politeness entered the spotlight of linguistic research in the late 1970s when the wave of interest was triggered by Leech and Brown and Levinson, it has become one of the key concepts in modern linguistics. It is said to go hand-inhand with language and social reality (Eelen 2001: 1). (...) According to Thomas (1996: 149), politeness is especially associated with pragmatics; she even refers to it as a sub-discipline of pragmatics. (DI10)

(11) As Uprichard and Byrne (2006: 668) put it, 'narratives are descriptions not of single systems but of the interweaving of complex systems,' because, '[p]eople never tell just the story of their own life; nor do they project simply in terms of themselves.'(AL 9)

When reviewing previous research, Anglophone writers invest more rhetorical effort in establishing links between sources (12) and evaluating prior research (13) to build up a discursive framework for their arguments and seek support for their views; the percentage of establishing links between sources is twice as high in the Introductions of $A L$ research articles than in DI research articles $(20.48 \%$ as compared with $10.11 \%$ ), while the percentage of evaluative citations is six times higher ( $4.79 \%$ as compared with 0.83$)$.

(12) Overall linguists vary in regard to this criterion, from not allowing any transformation of idioms (Wood 1981) to allowing 'different degrees of possible fixity or "frozenness", both syntactic and semantic'(Carter 1987: 58). (AL6)

(13) Swales $(1993,1996)$ refers to a number of stages in the publication process - the editor's letter to the reviewer, the actual review, the editor's summative letter to the author - that he suggests have 'their own generic sub-systems' (Swales 1996: 46) that often remain unavailable for public scrutiny or 'occluded'. We agree with Swales that these occluded genres are worthy of study, and that, as they are relatively straightforward with a clear and limited purpose, the components are easily identified. (AL3) 
Czech linguists are more likely to support their argument by providing examples of opinions and works of individual authors. In (14) the writer expresses disagreement with the view of the cited author in order to lay the foundations of the theoretical framework adopted in the study.

(14) Scollon (1998), for example, not only refutes the sender/receiver model but also claims that it is virtually impossible to define the so-called 'implied reader'. From our point of view, the theory of 'implied reader' is still at least partly valid because newspapers need to delimit their readership in order to get their share of the market, although they themselves realize that such a reader does not really exist (cf. Jančař́ková 2009, Reah 2002). (DI5)

The most obvious differences in Introductions between the two sub-corpora concern the choice of rhetorical functions of citations in the Establishing the niche move. While Anglophone writers typically opt for the steps of Indicating a gap or Counter-claiming (15), Czech linguists tend to show preference for the Establishing a tradition step (16). This seems to reflect divergences in the rhetorical traditions of the two discourse communities - the focus on contrasting alternative views and negotiating meaning and opinions in the Anglophone discourse community as opposed to the orientation towards respect for tradition within a single line of development in a specific field of the relatively small and traditionally mutually supportive Czech discourse community.

(15) This research challenges the view that language is strictly compositional, arguing instead that much of our everyday language use is composed of prefabricated expressions (see the reviews in Ellis 1996; Howarth 1996; Wray and Perkins 2000; Wray 2002). (AL5)

(16) The biblical texts have proved to be suitable for the purpose of the research in FSP and thus have supplied a syntactically rich source of discourse analysis studies (most notably Firbas 1992, 1995, Svoboda 1983, Adam 2004, 2006, Chamonikolasová \& Adam 2005). (...) The present paper attempts to trace the theme-rheme structure (as described on the clausal level) at the textual level, namely that of scripted sermons. (DI1)

There are notable differences in the range of rhetorical functions of citations in the Methods, Results and Discussion sections of research articles in the two sub-corpora. The spectrum of rhetorical functions of citations conveyed in both sub-corpora diminishes as compared to Introductions as a result of the limited use of peripheral citations. The range of functions in the $D I$ sub-corpus is particularly narrow in the Discussion section, where only attributions of ideas, activities and 
concepts occur (as compared to 5 citation functions in the $A L$ sub-corpus). In the Methods and Results sections the Czech writers use four functions of citations, with the attribution functions showing the highest percentage, as compared to seven and six functions respectively in the $A L$ sub-corpus, which shows a more significant representation of non-attributional citations, especially in the Results and Discussion sections.

The description of data collection and analysis procedures in the Methods section logically contains a higher percentage of citations attributing methods and approaches and stating the use of methods. Anglophone linguists tend to draw on broad methodological frameworks (17) and, especially in empirical articles, on previously tested methods, classifications and approaches to attest the procedural clarity and replicability of their research, which is also reflected by the high percentage of further reference citations (18) $(15.79 \%$ in the $A L$ subcorpus as compared to $1.92 \%$ in the $D I$ sub-corpus). While also referring to broad theoretical frameworks, Czech linguists show a preference towards statements of use of methods and concepts (19), thus substantiating terminological and procedural choices in their work.

(17) The present study is thus a straightforward genre study in the tradition of Swales's (1981, 1990) and Bhatia's (1993) work that sets up categories (moves) that reflect the editor's communicative purposes in the letter. (AL3)

(18) The part of the CSA which is designed to measure analytic processing is very similar to the Group Embedded Figures Test (GEFT) which is used to measure Field Independence (FI). FI refers to a person's ability to disembed a single item from its larger context (see Witkin et al. 1977). (AL1).

(19) We mainly draw on Schegloff's (1968) model of telephone openings, Schiffrin's model of opening encounters (1977) and studies dealing with Internet Relay Chat openings (Rintel et al. 2001, Ahti \& Lähtevänoja 2004). (DI9)

In both sub-corpora, the obligatory moves in the Results section - Reporting and Commenting on results - show prominent use of attribution citations intended to support suggested interpretations of research findings. Citations multifunctionality is illustrated by (20), where the reference to a well-known Czech scholar functions both as further reference and attribution citation and provides support for the writer's interpretation of results.

(20) Such an intonation pattern would then have to be assessed as a case of prosodic re-evaluating intensification ( $c f$. Firbas: 1992: 156-172), i.e. the kind of intensification induced by prosody which makes the theme-rheme relationship reversed. (DI6) 
The most striking difference in the rhetorical functions of citations in the Results section of the $A L$ and $D I$ sub-corpora concerns the percentages of occurrence of four citation functions: comparison of findings with sources $(15.18 \%$ in the $A L$ sub-corpus as compared to $1.96 \%$ in the $D I$ sub-corpus), further reference (9.82\% in the $A L$ sub-corpus as compared to $1.96 \%$ in the $D I$ sub-corpus), and statement of use (7.14\% in the $A L$ sub-corpus) and links between sources (8.04\% in the $A L$ sub-corpus), neither of which occur at all in the $D I$ sub-corpus. This is associated with the lack of the optional Reference to previous research (comparison) step in most $D I$ research articles (cf. Mur-Dueňas 2009 for similar results in a corpus of Spanish business management articles). It seems that after laying the theoretical background and explaining the analytical method applied in their research, Czech authors rarely use citations to support their findings and prefer to take responsibility for their claims without relating them extensively to the work of other scholars. This may be partially explained by a continuing tradition in orientation of most $D I$ research articles which seems to allow authors to assume that members of the small Czech linguistics discourse community are acquainted with the work done in this line of research. Anglophone authors, on the other hand, invest considerable effort in establishing the significance of their research results in the context of the field by critically comparing their findings to previous work and anticipating competing views (21).

This finding corresponds to that of Poulisse (1990: 143), except that Poulisse found the difference between the number of conceptual CSs used and the number of linguistic CSs to be a lot more marked. (AL1)

The closing Discussion (and conclusion) section follows the pattern established in the Results section, probably because these sections frequently overlap (cf. Yang \& Allison 2003). The only rhetorical function identified in the Results section of DI research articles is attribution of ideas, activities and concepts, and its frequency of occurrence is rather low (18 tokens for the whole sub-corpus); this suggests that Czech scholars in most cases simply summarize the results of their study without trying to contextualize them in a broader disciplinary context. The frequency of citations in the $A L$ sub-corpus is more than three times higher (58 tokens). Anglophone writers tend to comment on the limitations, significance and generalizability of their results, thus engaging in a dialogue with the reader aimed at negotiating their views and seeking support for their claims. The rhetorical functions matching these aims are establishing links between sources, comparison of findings with other sources (22), exemplification and further reference. 
(22) There is significant and growing evidence that female victims of these crimes are, for a wide variety of reasons, reluctant to report attacks, and that if the Crown Prosecution Service decides to pursue a prosecution following a complaint, victims feel vulnerable and intimidated by the trial-by-jury system in the UK. Both Lees (1996) and Ptacek (1999), writing about rape and domestic violence, respectively, report that female victims feel that it is they who are 'on trial' rather than the defendant. (AL4)

On the basis of this contrastive analysis, it can be concluded that the rhetorical functions citations in the $A L$ and $D I$ sub-corpora show similar tendencies: they convey a similar spectrum of citation functions, the most frequent rhetorical function is attribution and the least frequent functions are comparison with sources, evaluation and other. However, there is considerable variation in the variety and distribution of rhetorical functions of citation in the two subcorpora. Czech authors show a strong preference towards the use of attributional citations, most of which (both in terms of frequency and functional variety) are concentrated in the Introduction; the rest of the sections of $D I$ research articles display a limited range of rhetorical functions of citations. Anglophone authors use a wider range and higher frequency of rhetorical functions of citations in all sections of the AL research articles. These divergences indicate that Czech and Anglophone linguists differ in the ways they use citations to relate to previous disciplinary knowledge, establish the reliability of their results, seek support for their claims and construct their identity as members of the global and local academic communities.

\section{Conclusions}

Academic discourse is inherently bound with the linguacultural background of scholars as "cultures make available certain taken-for-granted ways of organizing our understandings" (Hyland 2009: 126) and influence the choices that writers make when interacting with their readers, including the perception of author identity and audience expectations, the organization of ideas and argument structure and the social value attributed to different texts (cf. Connor 2002). The interpersonal dimension of academic discourse is therefore bound to be affected significantly by the epistemological and literacy conventions of national disciplinary academic communities, which gives rise to intercultural variation.

The results of this contrastive study show that similarly to other interpersonal resources, such as authorial presence signalling devices, the use of conjunctives, hedges and boosters (cf. Dontcheva-Navratilova 2013a, 2016, Povolná 2013, 2016), the citation practices of Czech linguists differ from those of their 
Anglophone colleagues in terms of their rate, prevailing rhetorical functions and their distribution across research article sections, reflecting variation in the strategies the writers use to lay the foundations for their study, build up their authorial persona and seek support for their views and claims. These divergences seem to reflect variation in the intended readership and the respective epistemological and literacy traditions. Anglophone linguists who address a large international readership invest considerable rhetorical effort in engaging in a dialogue with their readers and positioning their research in a larger context, taking into consideration various established and recent sources. While seeking support for the validity and novelty of their claims, they strive to interconnect and evaluate numerous sources and establish relations between prior work and the writer's contribution to disciplinary knowledge. Czech linguists address primarily a local readership, though an international readership is also intended. When positioning their research within major theories, methods and approaches, they seem to assume that their readers know and share the same theoretical views and procedures. Persuasive argumentation is thus based on detailed presentation of research results rather than interactive resources helping writers to negotiate their views and claims. In recent years, however, Czech English-medium academic discourse has been influenced by Anglophone conventions of rhetoric promoted by the use of English as an academic lingua franca, reflecting the efforts of Czech scholars to publish in an international context. As previous research has shown (Dontcheva-Navratilova 2013b), Czech linguists are striving to accommodate themselves to the predominant Anglophone academic conventions in order to increase their chances of being accepted by institutional gatekeepers, such as journal editors and peer-reviewers.

To conclude, the results of this study have evidenced that in the context of globalized academia there is significant intercultural variation in the use of interpersonal rhetorical devices by writers from different linguacultural backgrounds. Obviously, the results of this research should not be overgeneralized. They should be verified by larger-scale studies considering the English- and Czech-medium discourse of Czech linguists in order to explore in greater detail the influence of Czech rhetorical conventions, the use of English as a lingua franca, the intended audience and the experience of the writers on variation in citation practices. In any case, the findings of this research have confirmed the relevance of an intercultural perspective on rhetoric for understanding how academic writers use intertextuality to persuade their readers to accept their views and claims. 


\section{Rhetorical Functions of Citations in Linguistics Research Articles: A Contrastive (English-Czech) Study}

\section{References}

Anderson, L. and Piazza, R. (2005) 'Talking about texts: Production roles and literacy practices in university seminars in Britain and Italy.' In: Bamford, J. and Bondi, M. (eds) Dialogue within Discourse Communities: Metadiscursive Perspectives on Academic Genres. Tubingen: Max Niemeyer Verlag. 147-178.

Bazerman, C., Little, J., Bethel, L., Chavkin, T., Fouquette, D. and Garufis, J. (2005) Reference Guide to Writing across the Curriculum. West Lafayette, IN: Parlor Press.

Bennett, K. (ed.) (2013) The Semiperiphery of Academic Writing. Basingstoke: Palgrave Macmillan.

Berkenkotter, C. and Huckin. T. (1995) 'You are what you cite: Novelty and intertextuality in a biologist's experimental article.' In: Blyler, N. and Thralls, C. (eds) Professional Communication: The Social Perspective. Newbury Park, CA: Sage. 109-127.

Bhatia, V. A. (2002) 'Applied genre analysis: A multi-perspective model.' Ibérica 4, 3-19.

Bhatia, V. A. (1993) Analysing Genre: Language Use in Professional Settings. London: Longman.

Biber, D., Connor, U. and Upton, A. U. (2007) Discourse on the Move: Using Corpus Analysis to Describe Discourse Structure. Amsterdam and Philadelphia: John Benjamins.

Bloch, J. and Chi, L. (1995) 'A comparison of the use of citations in Chinese and English academic discourse.' In: Belcher, D. D. and Braine, G. (eds) Academic Writing in a Second Language: Essays on Research and Pedagogy. Norwood, NJ: Ablex. 231-274.

Breeze, R. (2015) 'Citing outside the community? An investigation of the language of biography in top journals.' In: Plo Alastrué, R. and Pérez-Llantada, C. (eds) English as a Scientific and Research Language: Debates and Discourses. English in Europe, Vol. 2. Berlin and Boston: Mouton de Gruyter. 37-57.

Charles, M. (2006) 'The construction of stance in reporting clauses: A cross-disciplinary study of thesis.' Applied Linguistics 27 (3), 492-518.

Čmejrková, S. and Daneš, F. (1997) 'Academic writing and cultural identity: The case of Czech academic writing.' In: Duzsak, A. (ed.) Culture and Styles of Academic Discourse. Berlin: Mouton de Gruyter. 40-62.

Connor, U. (2004) 'Intercultural rhetoric research: Beyond texts.' Journal of English for Academic Purposes 3 (4), 291-304.

Connor, U. (2002) 'New directions in contrastive rhetoric.' TESOL Quarterly 34 (4), 493-510.

Dong, Y. R. (1996) 'Learning how to use citations for knowledge transformation: Nonnative doctoral students' dissertation writing in science.' Research in the Teaching of English 30 (4), 428-457.

Dontcheva-Navratilova, O. (2016) 'Cross-cultural variation in the use of hedges and boosters in academic discourse.' Prague Journal of English Studies 5 (1), 163-184.

Dontcheva-Navratilova, O. (2015) 'Cross-cultural variation in citation practices: A comparative analysis of citations in Czech English-medium and international English-medium linguistics journals.' In: Plo Alastrué, R. and Pérez-Llantada, C. (eds) English as a Scientific and Research Language: Debates and Discourses. English in Europe, Vol. 2. Berlin and Boston: Mouton de Gruyter. 185-205.

Dontcheva-Navratilova, O. (2013a) 'Authorial presence in academic discourse: Crosscultural analysis of the use of author-reference pronouns.' Linguistica Pragensia 1/2013, 9-30. 
Dontcheva-Navratilova, O. (2013b) 'The changing face of Czech academic discourse.' In: Bennett, K. (ed.) The Semiperiphery of Academic Writing. Basingstoke: Palgrave Macmillan. 39-61.

Fløttum, K., Gedde-Dahl, T. and Kinn, T. (2006) Academic Voices: Across Languages and Disciplines. Amsterdam and Philadelphia: John Benjamins.

Flowerdew, J. (2008) 'Scholarly writers who use English as an additional language: What can Goffman's “Stigma” tell us?' Journal of English for Academic Purposes 7, 77-86.

Flowerdew, L. (2004) 'The argument for using English specialized corpora to understand academic and professional language.' In: Connor, U. and Upton, T. (eds) Discourse in the Professions. Amsterdam: John Benjamins. 11-33.

Garfield, E. (1965) 'Can citation indexing be automated?' In: Stevens, M. E., Guiliano, V. E. and Heilprin, V. B. (eds) Statistical Association Methods for Mechanized Documenation. Washington, DC: National Bureau of Standards Miscellaneous Publication. 189-192.

Harwood, N. (2009) 'An interview-based study of the functions of citations in academic writing across two disciplines.' Journal of Pragmatics 41 (3), 497-518.

Harwood, N. (2008) 'Citers' use of citees' names: Findings from a qualitative interviewbased study.' Journal of the American Society for Information Science \& Technology 59 (6), 1007-1011.

$\mathrm{Hu}, \mathrm{G}$. and Wang, G. (2014) 'Disciplinary and ethnolinguistic influences on citation in research articles.' Journal of English for Academic Purposes 14, 14-28.

Hyland, K. (2009) Academic Discourse: English in a Global Context. London and New York: Continuum.

Hyland, K. (2003) 'Self-citation and self-reference: Credibility and promotion in academic publication.' Journal of the American Society for Information Science and Technology 54 (3), 251-259.

Hyland, K. (2000) Disciplinary Discourses: Social Interactions in Academic Writing. Harlow, UK: Pearson Education.

Hyland, K. (1999) 'Academic attribution: Citation and the construction of disciplinary knowledge.' Applied Linguistics 20 (3), 341-367.

Lillis, T., Hewings, A. and Vladimirou, D. (2010) 'Who's citing whose writings? A corpusbased study of citations as interpersonal resource in English medium national and English medium international journals.' Journal of English for Academic Purposes 9, 102-115.

Lin, C., Chen, Y. and Chang, C. (2013) 'Citation functions in social sciences and humanities.' ASIST 2013, November 1-6, 2013, Montreal, Quebec, Canada.

Mansourizadeh K. and Ahmad U. K. (2011) 'Citation practices among non-native expert and novice scientific writers.' Journal of English for Academic Purposes 10, 152-161.

Moravcsik, M. J. and Murugesan, P. (1975) 'Some results on the function and quality of citations.' Social Studies of Science, 5 (1), 86-92.

Mur-Dueňas, P. (2009) 'Citation in business management research articles.' In: SuomelaSalmi, E. and Dervin, F. (eds) Cross-Cultural Linguistic and Cross-Cultural Perspectives on Academic Discourse. Amsterdam and New York: John Benjamins

Oppenheim, C. and Renn, S. P. (1978) 'Highly cited old papers and reasons why they continue to be cited.' Journal of the American Society for Information Science 29, 225-231.

Petersen, M. and Shaw, P. (2002) 'Language and disciplinary differences in a biliterate context.' World Englishes 21 (3), 357-374. 


\section{Rhetorical Functions of Citations in Linguistics Research Articles: A Contrastive (English-Czech) Study}

Petrić, B. (2007) 'Rhetorical function of citations in high- and low-rated master's theses.' Journal of English for Academic Purposes 6, 238-253.

Petrić, B. and Harwood, N. (2013) 'Task requirements, task representation, and selfreported citation functions: An exploratory study of a successful L2 student's writing.' Journal of English for Academic Purposes 12, 110-124.

Povolná, R. (2016) 'A cross-cultural analysis of conjuncts as indicators of the interaction and negotiation of meaning in research articles.' Topics in Linguistics 17 (1), 45-63.

Povolná, R. (2013) 'On cross-cultural variation in the use of conjuncts in research articles by Czech and native speakers of English: Can conjuncts contribute to the interactive and dialogic character of academic texts?' In: Plo Alastrué, R. and Pérez-Llantada, C. (eds) English as a Scientific and Research Language: Debates and Discourses. English in Europe, Vol. 2. Berlin and Boston: Mouton de Gruyter. 115-140.

Samraj, B. (2013) 'Form and function of citations in discussion sections of master's theses and research articles.' Journal of English for Academic Purposes 12, 299-310.

Shaw, P. (1992) 'Reasons for the correlation of voice, tense and sentence function in reporting verbs.' Applied Linguistics 13 (3), 302-319.

Shaw, P. and Pecorari, D. (2013) 'Source use in academic writing: An introduction to the special issue.' Journal of English for Academic Purposes 12, A1-A3.

Small, H. (1982) 'Citation context analysis.' In: Dervin, B. and Voigt, M. J. (eds) Progress in Communication Sciences, Vol. 3. Norwood, NJ: Ablex. 287-310.

Swales, J. (2004) Research Genres. Cambridge: Cambridge University Press.

Swales, J. (1990) Genre Analysis. Cambridge: Cambridge University Press.

Swales, J. (1986) 'Citation analysis and discourse analysis.' Applied Linguistics 7, 39-56.

Thomas, S. and Hawes, T. (1996) 'Citation as persuasion in research articles.' TEANGA: The Irish Yearbook of Applied Linguistics 16, 53-72.

Thompson, G. and Ye, Y. (1991) 'Evaluation in reporting verbs used in academic papers.' Applied Linguistics 12 (4), 356-382.

Thompson, P. (2000) 'Citation practices in PhD theses.' In: Burnard, L. and McEnery, T. (eds) Rethinking Language Pedagogy from a Corpus Perspective. Frankfurt: Peter Lang.

Thompson, P. and Tribble, C. (2001) 'Looking at citations: Using corpora in English for academic purposes.' Language Learning \& Technology 5 (3), 91-105.

White, H. (2004) 'Citation analysis and discourse analysis revisited.' Applied Linguistics 25 (1), 89-116.

White, H. (2001) 'Authors as citers over time.' Journal of the American Society for Information Science and Technology 52, 87-108.

Vázquez, I. and Giner, D. (2008) 'Beyond mood and modality: Epistemic modality markers as hedges in research articles. A cross-disciplinary study.' Revista Alicantina de Estudios Ingleses 21, 171-190.

Yang, R. and Allison, D. (2003) 'Research articles in applied linguistics: Moving from results to conclusions.' English for Specific Purposes 22, 365-385.

Olga Dontcheva-Navratilova is Assossiate Professor of English Linguistics at Masaryk University in Brno, Czech Republic. She specializes in discourse analysis, stylistics and pragmatics, with a focus on academic and political discourse. She has published many articles on topics related to her research interests and is the author of Analysing Genre: The Colony Text of UNESCO Resolutions (2009), in 
which she analyses the distinctive features of the colony text type as represented in the genre of resolutions, and Coherence in Political Speeches (2011), in which she explores the interplay of topical, evaluative and textual coherence in political discourse. She is co-editor of Coherence and Cohesion in Spoken and Written Discourse (2009) and Discourse Interpretation: Approaches and Applications (2011), published by Cambridge Scholars Publishing. She is co-editor of the linguistics journal Discourse and Interaction.

Address: Assos. Prof. Mgr. Olga Dontcheva-Navratilova, Ph.D., Department of English Language and Literature, Faculty of Education, Masaryk University, Porríčí 9, Brno 603 00, Czech Republic. [e-mail: navratilova@ped.muni.cz] 